\title{
TOURISTS’ PREFERENCES FOR ECOTOURISM PLANNING AND DEVELOPMENT AROUND NYUNGWE NATIONAL PARK, RWANDA
}

\section{Kambogo ${ }^{1}$, J.P. Bizimana ${ }^{2}$}

1 Rwanda Development Board, Tourism Department, Nyungwe National Park, PoBox: 6239, Kigali, Rwanda.

2 University of Rwanda; College of Science and Technology, Geography Department; and Centre for Geographic Information Systems and Remote Sensing (UR-CGIS), PoBox: 212, Huye, Rwanda.

\section{Abstract}

Tourist destinations promote eco-tourism in achieving both nature conservation and income generation. To effectively provide services that facilitate achievement of those goals, decision-makers need to understand and incorporate tourists' preferences for nature appreciation, infrastructure development and use restrictions in national parks. The lack of data on tourist's preferences and the changing needs of tourists in Rwanda need to be well understood for ecotourism planning and development. This paper presents tourists' preferences in relation to ecotourism planning and development in Nyungwe National Park, southwestern Rwanda. The aim of the study was to illustrate tourists' preferences and their attitudes about ecotourism products within the park. Data used in this study were gathered using survey questionnaires that were distributed to both foreign and local tourists. GPS device was used to locate the attributes visited or planned to be visited by tourists, and the tourism products which need to be developed within and around the park. We then mapped these locations to visualize tourism attributes in order to guide decision makers in ecotourism planning and development in Rwanda. Results demonstrated that tourists were constrained by time and price to stay longer in the park. Tourists were satisfied with the guiding and service delivery. Tourists' preferences were: revising the price; improved product quality; creation of scenic viewpoints; improved service quality; improved infrastructure and information on the park as well. The study found that the park managers need to reconsider tourist's preferences while planning and developing ecotourism in Rwanda. Improving the way of disseminating information to tourists can be an added value to increase the number of tourists and revenues to the park. A study on consumers' preferences is substantially beneficial to allow park managers to effectively respond to tourists' needs and requirements.

Key words: Ecotourism, tourist's preference, planning, Nyungwe, Rwanda

\section{Introduction}

Over time, an increasing number of destinations have opened up and invested in tourism development, turning modern tourism into a key driver of socio-economic progress through export revenues, the creation of jobs and enterprises, and infrastructure development (Luna-Nevarez and Hyman (2012); UNWTO, 2012). According to NWTO's forecast, international arrivals are expected to reach nearly 1.6 billion by 2020 (UNWTO, 2012). Africa 
is one of the continents with a significant potential for developing tourism (Ngenzi, 2009). The number of travels to protected areas in Africa is increasing due overall expansion of tourism, development of international transport networks and the growing interest amongst tourists in learning more about natural and cultural heritage of their destinations (Tapper and Cochrane, 2005). In many countries, visits to protected areas have been increasingly promoted because they provide economic incentives for conservation (Sutherland, 2008). Since 2000, tourism was identified as a priority sector to achieve the country's development goals of Rwanda Vision 2020; and significant progress in developing the tourism sector have increased tourism revenues (UNWTO, 2008). Nyungwe was designated a Forest Reserve in 1933, but has only been managed since the mid-1980s. Nyungwe has unique potential to be a highly tourist attraction because of its exceptional primate viewing, bird watching, mountain hiking and mountain flora. Due to this potential, NNP was recognized as Rwanda's leading ecotourism and adventure destination that complements other tourism destinations while providing optimal economic benefits to neighboring communities (Rwanda Development Board, 2011). NNP offers an opportunity to visit chimpanzees, Angolan black and white colobus monkeys, grey-cheeked mangabeys and blue monkeys habituated for the tourist experience (Plumptre et al., 2002).

To manage NNP, different planning policies were developed in order to facilitate the private sector in tourism investment opportunities including the construction of hotels (Ngenzi, 2009). However, some of these policies like the concession policy, the tourism value chain analysis and the bird watching management plan in NNP have been undertaken without taking into account information about tourists' preferences (Hansen, 2012). The lack of sufficient data and information on the tourist market in NNP limits the understanding of consumer needs and preferences to effectively plan and develop ecotourism products (Government of Rwanda, 2009b; Rwanda Office of Tourism and National Parks, 2005). Compared to consumer durable goods and food products, consumer preferences on tourism are less developed (Van Raaij, 1986) and scientific understanding about the preferences and behavior of ecotourists remains incomplete (Perkins and Brown, 2012). It is against this background that this research seeks to fill a gap in understanding tourists' preferences for effective ecotourism planning and development in and around NNP.

The study aims at illustrating tourists' preferences and their attitudes about ecotourism products in NNP. The specific objectives that guided this research were to (1) identify and determine the park's main attributes that attract tourists; (2) investigate tourist's top reasons to visit NNP; (3) determine tourists' attitudes towards the locally offered ecotourism products and services; and (4) verify whether and why knowledge of visitors' preferences helps in ecotourism planning and development in Rwanda. These expected research outcomes 
represent opportunities for local tour agents and tourism marketers in providing appropriate tourism products and services. They can use tourist experiences to understand the types of tourism packages to offer to different tourism segments.

\section{Materials and Methods}

\subsection{Study area description}

NNP is located in the southwest of Rwanda. It covers an area of more than $1030 \mathrm{~km}^{2}, 980 \mathrm{~km}^{2}$ of tropical montane forest. It is contiguous with Kibira National Park in Burundi. Together, these protected areas form the largest block of forest in Eastern Africa (UNEP, 2008, 2011). Figure 1 shows the location of NNP in Rwanda.

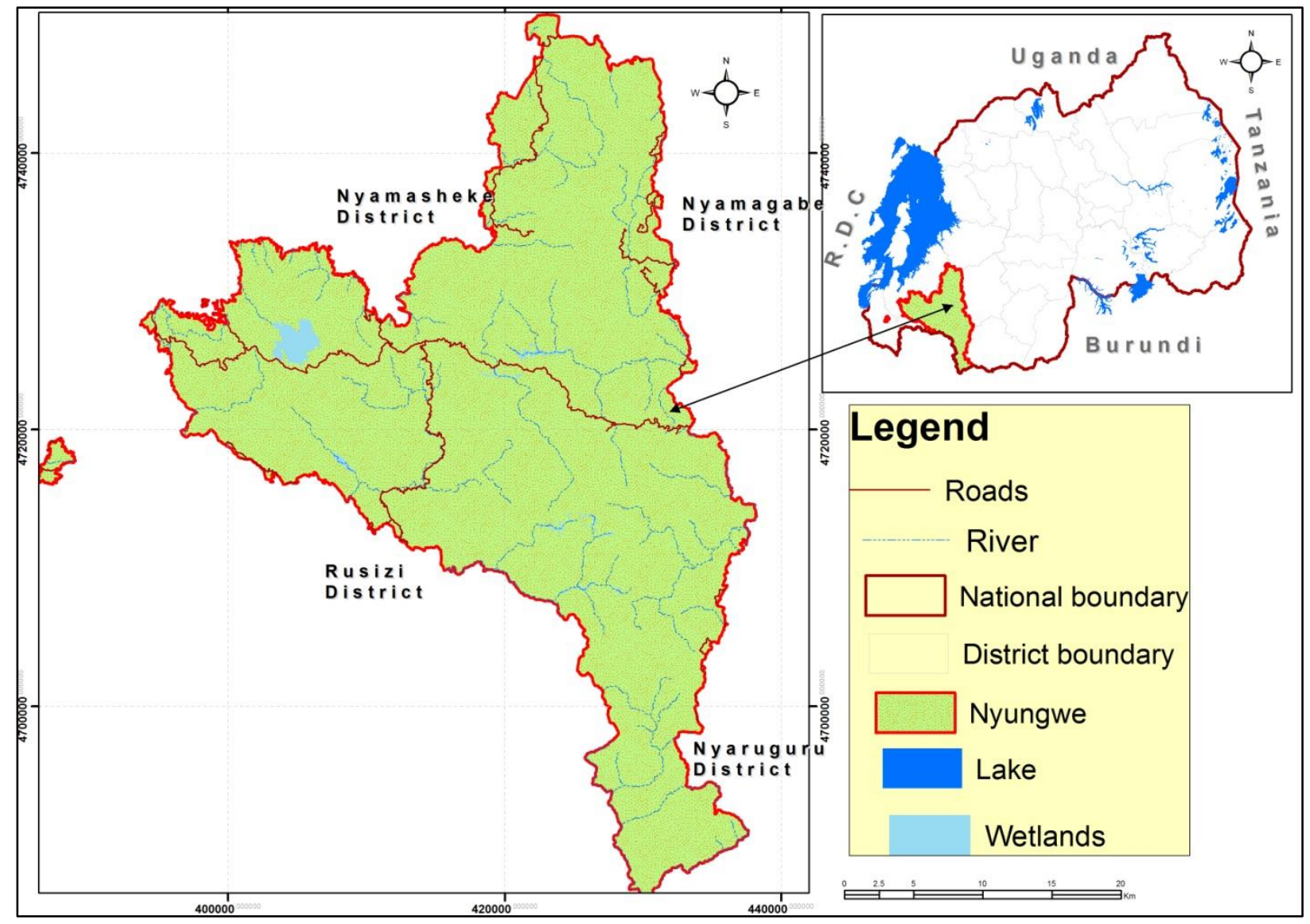

Figure 1: Location of NNP in Rwanda

As a tropical montane forest, NNP lies between 1,600 and 2,950meters of altitudes. The forest is highly dissected with steep slopes. The only flat areas within the park are Kamiranzovu and Uwasenkonko swamps. It is recognized as a site of global importance for its biodiversity and endemism values, which are among the highest within Albertine Rift eco-region (Byers et al., 2014; Chemonics International, 2008). Nyungwe possesses one of the most species rich montane rainforest primate communities in Africa (Vedder, 1988a, b). Its biodiversity includes 75 mammals, 275 bird species, 125 butterfly species, over 260 species of trees and climbers and more than 148 orchid species (Gapusi, 2007; Plumptre et al., 2007; Plumptre et al., 2002). The park also 
includes Cyamudongo Forest located within 10 kilometers from the main forest to the southwest, a home of chimpanzees and monkeys. This wealthy biodiversity complements the mountain gorilla which is the main tourist attraction in Rwanda (REMA, 2011).

Along with rich biodiversity, Nyungwe is also an important water catchment for Rwanda. NNP contributes 70 percent of the country's rainfall (Masozera, 2002). As furthest source of the Nile River, it supplies nearly 75 percent of the dry season river flow in country's principal river system (Plumptre, 2003; Plumptre et al., 2004; Plumptre et al., 2002). Moreover, rivers and streams originating from Nyungwe flow both east and west into Nile and Congo basins and provide most parts of the country with stable sources of water. Furthermore, Kamiranzovu and Uwasenkonko swamps are important water reservoirs which contain some of the largest peat bodies in Africa (Hamilton, 1982).

Rwanda, being one of the most heavily populated areas of Africa, means that Nyungwe is however under constant threat from anthropogenic pressures (UNEP, 2011). Since 1990s, Nyungwe forest cover has decreased due to human pressures, lack of sustainable sources of income for surrounding communities, limited awareness and lack economic incentives for sustainable use of biodiversity (Government of Rwanda, 2009a; Seyler and Mugemana, 2003). However, this protected area remains one of the most significant natural forests in East Africa.

Ecotourism in NNP was established by Wildlife Conservation Society in collaboration with ORTPN in the late 1980s (Rwanda Office of Tourism and National Parks, 2005). Since this period, the main tourism attractions were based on primate viewing especially chimpanzees and Colobus monkeys, and guided hikes on a developed network of trails. Figure 2 shows the tourism and conservation zonation map within and around of NNP. 


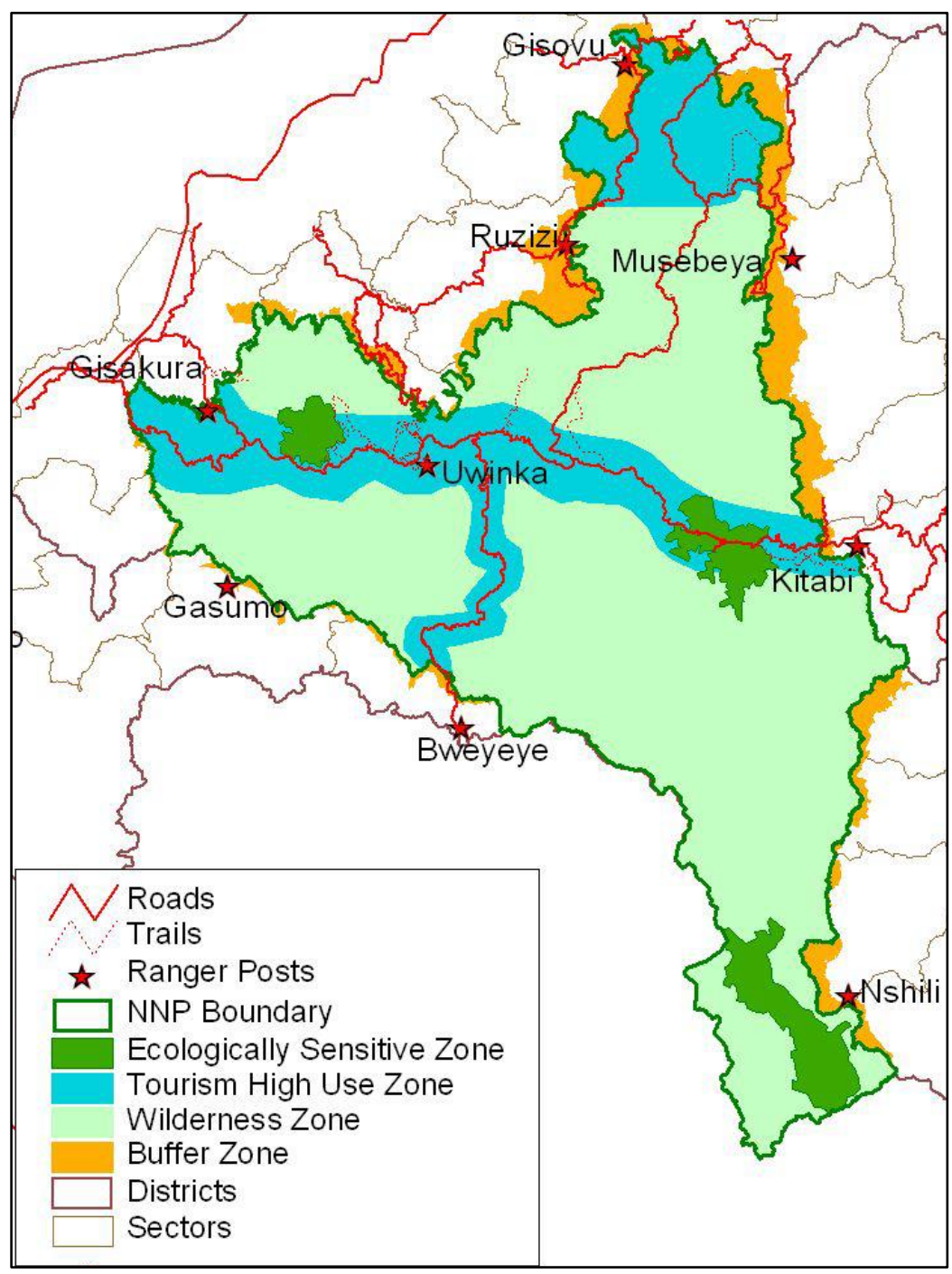

Figure 2: Nyungwe National Park zonation map

Unfortunately, the 1994 genocide perpetrated against the Tutsi resulted in the destruction of many of the tourists' facilities at Uwinka and negatively affected tourism at Nyungwe. Since 1994, the number of tourist remained below 1,000 visitors. It is only in 2003 that this number increased to 1,785 visitors (Walpole, 2004b). Such a low visitation level can be explained by a poor image, lack of knowledge by consumers of tourism in Nyungwe due to limited marketing and promotion of tourism and uncertainty in guaranteeing chimpanzee viewing.

The tourist flow to NNP has grown rapidly since 2005 when the forested became a national park. Tourists are more attracted by the recently opened canopy walk, chimpanzee and colobus-tracking opportunities, hiking trails and birding (Crawford, 2012). The recent installation of a canopy walk and Uwinka Visitor Center, the delineation of the Congo/Nile divide trail, the improvement of chimpanzee habituation in Cyamudongo Forest and the Mayebe group in the main forest block, and enhancement of the ranger-based monitoring are the main tourism and conservation efforts in NNP which resulted in sharp increase of tourists as showed in Figure 3. 


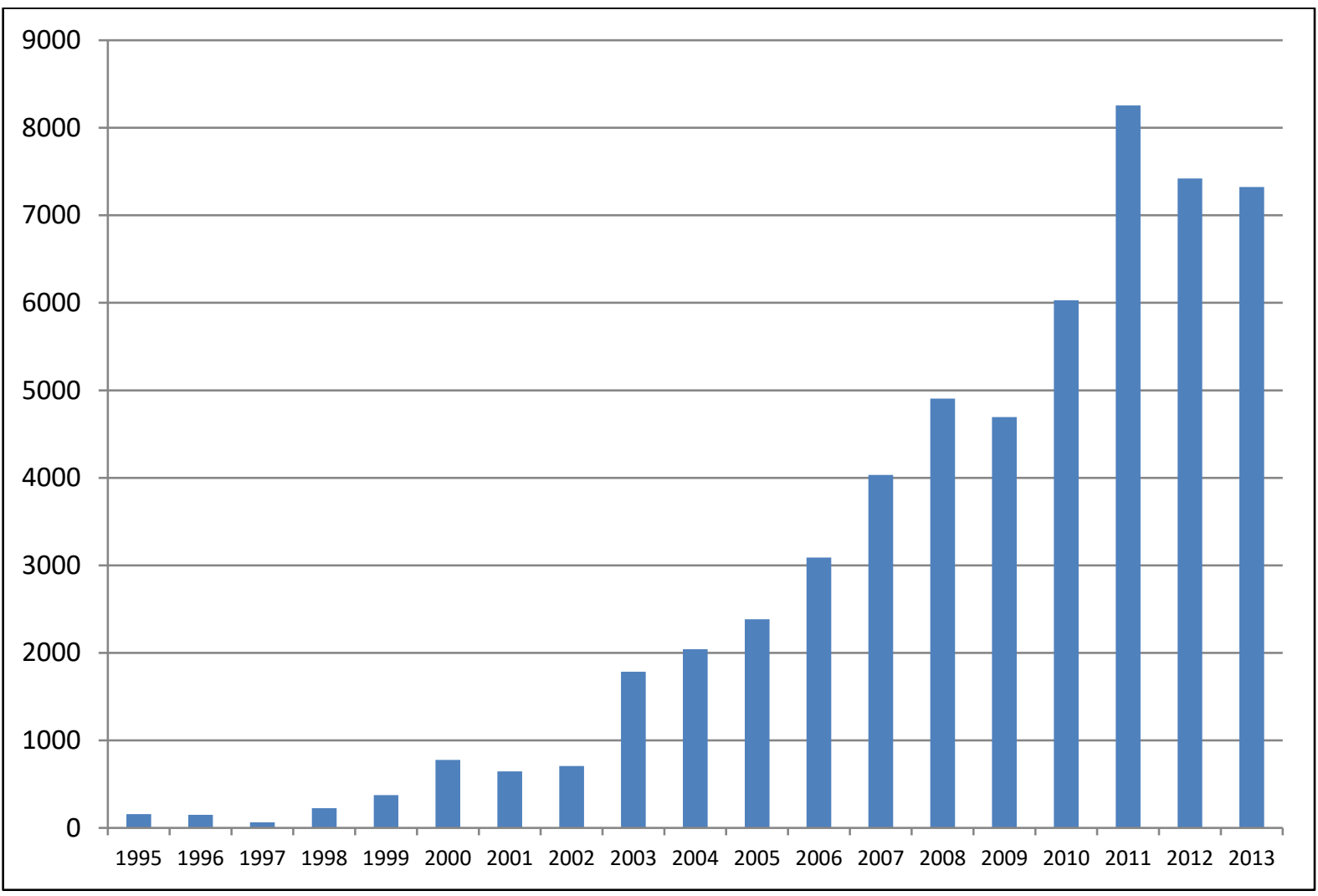

Figure 3: Tourists numbers in NNP between 1995 and 2013

These tourism infrastructure developments add value to the Nyungwe tourism product portfolio by offering a range of opportunities to attract and keep foreign tourists and significantly boosting tourism sector earnings in Rwanda (Cowles et al., 2013). Still, the limited number of visitors is not a broad base (Hansen, 2012) from which to generate income for poor populations bordering Nyungwe (Richmond et al., 2015). Although NNP is doing an excellent job in biodiversity conservation while providing a range of opportunities to visitors, improving customer service of guides, institutionalizing canopy walk, and road infrastructure maintenance and upgrading are areas where improvement could be made (Cowles et al., 2013).

\subsection{Data collection}

A literature review was adopted to better understand the key concepts related to tourist's preferences and ecotourism planning and development. A desk study helped to collect available data and information including ecotourism planning policy documents and historic data on NNP before in depth survey and interview take place. Its purpose was to build an understanding of tourism's status and visitors' trends; to design the sampling frame and methodology; define the scope of the research; delineate the geographic area; and specify the target populations. Nonprobability and purposive sampling technique was applied to a total number of visitors to NNP based on statistics of visitors provided by Rwanda Development Board, Tourism and Conservation Department. A survey questionnaire was addressed to 316 tourists, keeping in mind that NNP 
receives an average 600 tourists per month. The tourists were selected on the basis of their arrival and availability at Nyungwe Forest Lodge, Nyungwe tope View Hill Hotel, Gisakura and Uwinka visitor centers.to from June to August 2014. Since the survey was conducted in high season tourism activity, there is a confidence that the chosen sample is truly representative of the entire study population. During the survey, there was a systematic monitoring of the survey to make sure that the number of anticipated questionnaires was attained and all the questioned were answered. The population under study covered both domestic and foreign tourists visiting Nyungwe National Park as well as East African citizens because the park statistics report put tourists into four categories: Foreign visitors, foreign residents, Rwandan citizens and East African citizens.

Park guides administered the questionnaires to tourists. Prior to questionnaire distribution, park guides were briefed on proper administration and understanding of the questions. Questionnaires were discussed together with the researchers to ensure their validity. They were further subjected to a pre-test that involved a random sample of forty respondents with characteristics similar to those of the target population. The pre-survey helped to establish the appropriateness of the questions and their reliability. Questionnaires were administered by the park guides and researchers in four different locations: Uwinka, Gisakura and Kitabi Reception Centers, and Nyungwe Forest Lodge. Questionnaires were answered by tourists visiting NNP, mainly at three hotels near the park, and three tourism reception centers of the park. The survey was conducted from June to August 2014. Interviews were held with park managers and hoteliers to supplement information obtained from questionnaires. Three hoteliers were approached, namely Nyungwe Forest Lodge, Top View Hill Hotel and Gisakura Guest House all located around the NNP western gate. Managers interviewed include the chief park warden, tourism warden, research and monitoring, community conservation and law enforcement wardens.

Global Positioning Systems (GPS) was used to locate the attributes visited or planned to be visited by tourists; and the tourism products which need to be developed within and around the park. ArcGIS software was applied to map and visualise the tourism attributes. Its application in tourism can help to guide the decision-making process ecotourism planning (Kushwaha et al., 2011; McAdam, 1999). Collected primary data were edited from the field to check for errors, completeness and consistency of answers. Data were then categorized, sorted, and coded to facilitate subsequent data entry and analysis. Data were analyzed by using (SPSS) software. The output of the analysis was presented in form of output tables, percentages and graphs.

\section{Results and discussions}

\subsection{Activities visited or planning to visit}

Nature walks are no longer regarded as main activities in the park but as secondary products or the way to embark on more elaborated activities such as canopy walk, experience of waterfall, colobus and chimpanzee tracking. 


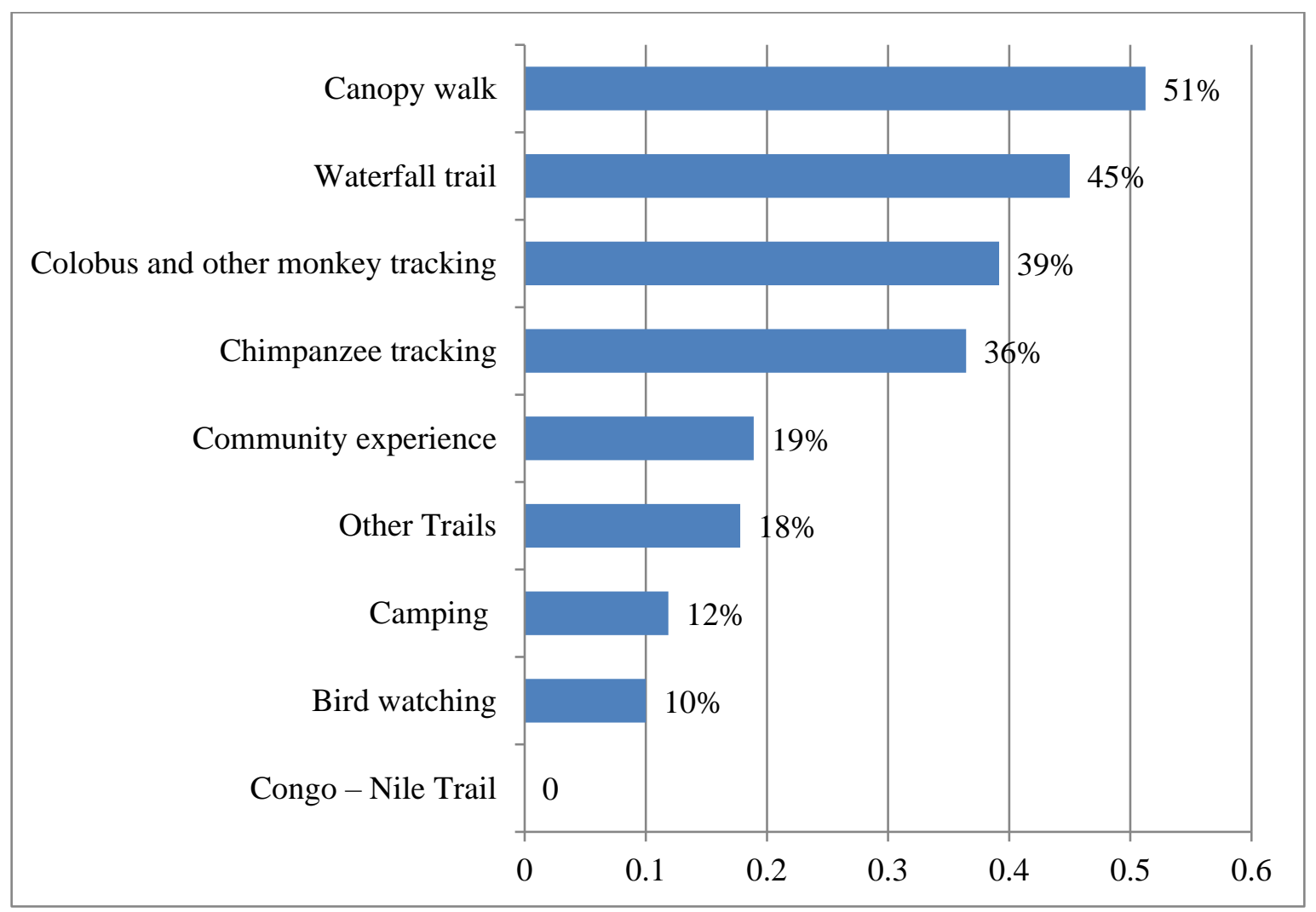

Figure 4: Attributes that attract tourists to the park

The most attractive tourist attributes are the canopy walk; the waterfall trail; and colobus and monkeys tracking (Figure 4). The canopy walk is a recent tourism product developed in 2010 by Rwanda Development Board to diversify tourism products in the park. This is the first ever hanging platform above a steep and deep valley stretching across the massive forest, allowing therefore tourists to view different animal species in Nyungwe Forest. Based on an evaluation of USAID investments report, the Nyungwe canopy walk increased the number visitors to Nyungwe rain forest. This canopy walk appears to have stimulated RDB interest in positioning NNP as an adventure tourism destination (Cowles et al., 2013). Nyungwe canopy walkway provides a unique experience to tourists by taking them through the green foliage of the tree top thus providing a panoramic view of the surroundings. Experience from other countries showed that this kind of walkway offers visitors a more natural perspective and a amazing way of experiencing the rainforest (bin Ramlan et al., 2011).Canopy activities increase the economic benefits from standing forest and thus change the economic equation towards conservation. The sustainability of the canopy walk has however to manage some environmental impacts including erosion, cutting of corridors into the forest, massive steel platforms and towers. Noise impacts also exist from big group sizes, unguided tours and chainsaw like sounds produced by the rolls on the steel cables (Seibel, 2005; Seibel, 2013). The RDB tourism department that is responsible for managing the canopy walkway can use these findings in deciding on the best marketing strategies and 
management practices required concerning the sustainability of Nyungwe Canopy Walkway as a nature-based tourism product.

\subsection{Other products to be developed in and around NNP}

Respondents ranked the importance of other tourism products that they would like to have available within and outside the park and suggested other possible tourism products they would want to participate in. The Star Gazing and night visit, Zip line/ rope way or cable car, and primate's sanctuary are the main products that have to be developed in NNP as proposed by the majority of tourists (Figure 5). The Zip-line tour is an aerial adventure experience in which participants soar by gravity-assisted flights along a series of parallel zip-lines made of galvanized steel posts and cables. A cable car system has a suspension and traction cable carrying passenger carriers such as lift chairs. It is guided around two deflection pulleys in which a conveyor device conveys passengers from an entrance gate to a boarding point at which passengers board to carriers (Fuchs, 1997). Cable cars are mainly used to transfer tourists from the main facilities in the village to the top of the mountain. They have been one of the main driving forces behind the alpine tourism because they foster mountain tourism and induce huge direct and indirect monetary benefits in peripheral areas (Fuchs, 1997) such as Nyungwe rainforest. Thus, the cable car system can be implemented at NNP by tourism entrepreneurs as one the ways of differentiating the product to meet the tourist's preferences especially during the rainy season.

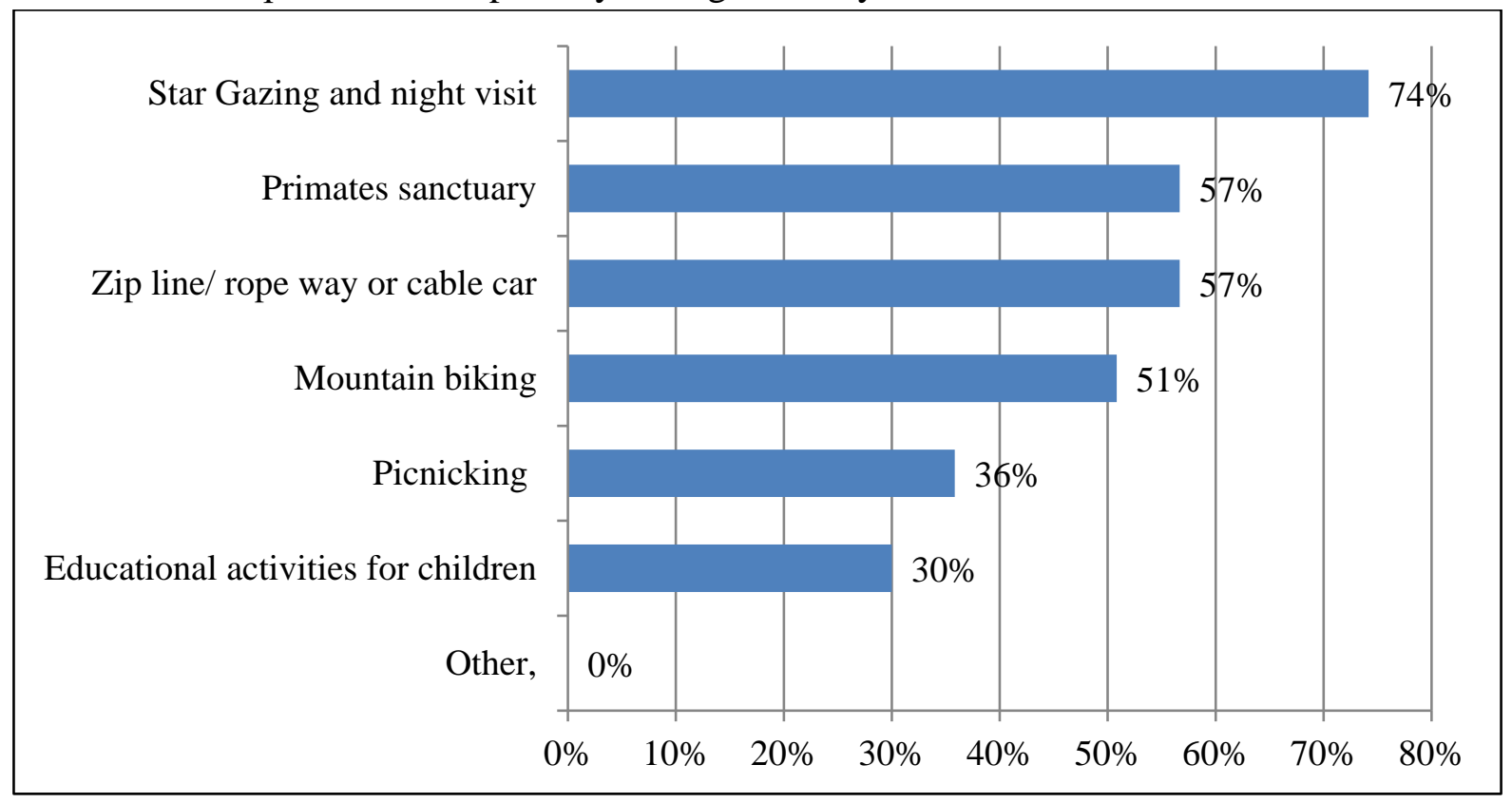

Figure 5: Preferred products within the park

A recent trail management plan for the park developed in 2012 suggested the same activity at some designated areas. Providing mountain biking will enhance the overall visitor experience for visitors to the park, as well as enhance ecotourism opportunities locally and regionally. Uwinka Visitor Center can be the focus of several mountain bike opportunities. Visitors could ride the park road 
west to the Karamba Trail and park their bikes, hike and then return. They could continue to Gisakura. The southern segment of the Congo / Nile Trail is on gentle grades, in good condition that would support mountain biking. A loop could be investigated to connect to the Bigugu trail. Pindura road from the park road south to Busoro could be mountain biked. Visitors could also mountain bike the park road east to Kitabi (Sharlow and Duffy, 2012). Approximately 36\% of the respondents want to enjoy picnicking in the park and $74 \%$ suggested star gazing and night visits.

There is no readily available market profile data on star gazing tourists, although this type of product would be classified as a viewing and learning activity in which more than 150 million Americans and Canadians participate. This product would focus on providing visitors with an educational and learning experience in which they find out more about the stars and the night sky. Star gazing and astronomy are an excellent complement to other nature based activities such as birding, wildlife viewing as well as adventure activities such as canoeing, biking and hiking. The tours and viewing locations would change according to the stars and constellations, which can be viewed at a particular time.

From the survey, a primate sanctuary was mostly recommended while a small number of the respondent suggested that the educational activities for the children should be added in the park. At the time of the survey, the products were not available in NNP. Historically, the role of primate sanctuaries was simple: provide care, re-socialization and a long-term, stable environment for confiscated primates across Africa. Many sanctuaries started as the direct response to the frequent sale and mistreatment of primates across Africa due to the wild animal trade and deforestation, which allowed large numbers of primates to be killed and the infants sold. As sanctuaries have grown in size and number it has become clear that simply being a home for primates is not enough, they now have a bigger role to play not only in raising awareness but also reducing the plight of primates in the wild. These sanctuaries are hubs of activities that include: i) facilitating the reintroduction of groups of chimpanzees, bonobos, gorillas, mandrills and colobus from captivity to the wild, ii) research on the behavior, ecology, physiology and cultures of primates and iii) education of both locals and tourists in conserving our natural environment. When asked why the sanctuary would be desireable while it is easy to track primates in the park, some respondents mentioned that not all types of tourists can go to track primates due to limited number of people allowed to visit chimpanzees at any one time for example, age limit and limited time. It is an opportunity for more people to understand how these species survive. However, though the sanctuaries are a source of tourism revenues, they are expensive to maintain in terms of resources either human or financial and have ethical concerns.

Tourists were given a list of activities that can be found outside the park in surrounding communities such as tea plantation and tea factories tours, village tour, cultures and handcraft experience, as well as shopping centers and asked to rank them. Communities around the park are supposed to benefit from ecotourism. 


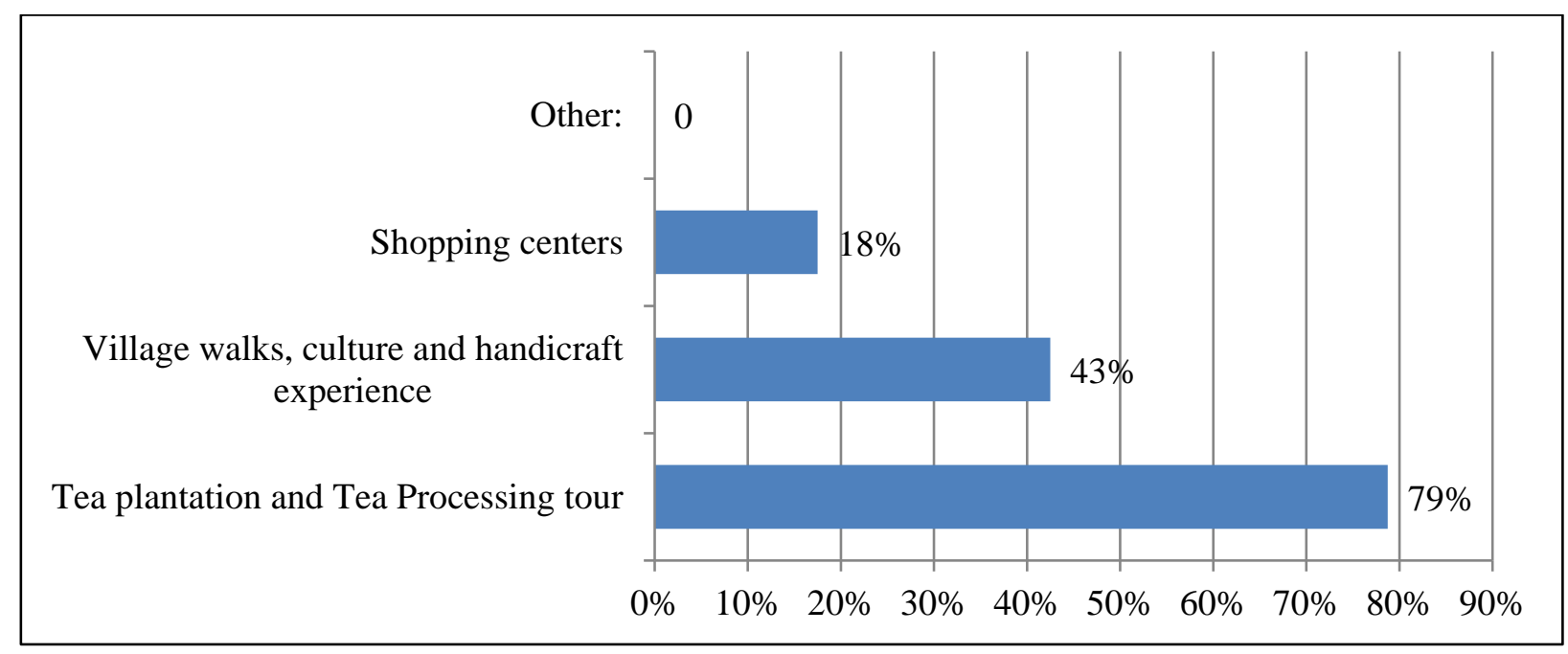

Figure 6. Preferred products outside the park

Tourists mentioned tea plantation and tea processing tour as the first product ranked as desirable (Figure 5). NNP is surrounded by tea plantations and factories with beautiful scenery. Tea means many things to many people; it has an immensely rich and intriguing history and can be considered to be a plant, an agricultural product, a beverage, a meal service or pastime. Tea is closely connected with the ancient and modern world of trade and travel; and has become an attractive tourism product and many people drink it without seeing how it is processed (Jolliffe, 2007). Tea tourists typically enjoy tea drinking and are often willing to buy tea as a souvenir (Cheng et al., 2010; Cheng et al., 2012). Other studies of ecotourism potentials (Mehta, 2007; Mehta, 2010; Walpole, 2004a) highlighted the potential for tea plantation tours and luxury eco-lodges on the tea-forest periphery. As Nyungwe National Park is surrounded by many tea plantation and tea factories, this location also provides some marketing suggestions for this niche market of tea from Rwanda highlands (Cheng et al., 2010). Thus, the development of tea plantations around NNP expands new roads for tourism attractions (Masozera and Alavalapati, 2004). This finding implies a range of marketing approaches that could greatly assist the penetration of national tea products into local hotels. For example, simply increasing the level of tea marketing and sales activity to the hotels will undoubtedly help local tea-leaves appear in local hotels. A broad range of stakeholders need also to be actively and explicitly brought into the tea tourism chain (Huang, 2006). It would also be very beneficial if the local tea producers and sales companies created a marketing strategy to promote the tea tourism image in Rwanda.

Finally, village walks are ranked second among the most attractive tourism products outside NNP. There are currently two cultural centers (Banda and Kitabi Villages) around the park but due to their inaccessibility, this activity is not well developed, the second one is still under development. Shopping centers were also indicated as preferential by a smaller proportion of the tourists. The existing ones are not at a standard of meeting tourists' needs and wants. Even if the rural village tourism opportunity at initial stage around NNP, other studies have however showed that village- 
based tourism creates community development, improves agricultural markets, generates income and brings random good fortune (Lepp, 2007). To attract more visitors, planning for eco-tourism development should identify or develop other rural villages around NNP with intrinsic significance and unique character; with close proximity to natural, historical or cultural sites (Fagence, 1998).

Although it was not emphasized by tourists, the growing number of farmers in coffee production, which is paralleled with the increase of coffee washing stations around NNP, suggests that coffee tourism can be regarded as a niche for tourism market in Rwanda. Coffee tourism is related to the consumption of the coffee, history, traditions, products and culture of a destination (Jolliffe, 2010). The development of coffee tourism projects around NNP where visitors are able to learn about coffee-making could provides poor farmers the opportunity to link with wealthy consumers and to take greater control of their product, and add value through developing various tourism activities associated with coffee (Anbalagan and Lovelock, 2014). This finding supports the local initiative of the GoR which recognizes coffee tourism as a potential attraction product to complement the eco-tourism market which could increase length of stay and visitors spend (Government of Rwanda, 2009b). It can also improve the quality of agricultural products and services, while developing multiple functions of agro-tourism leading to wider economic, environmentaland social benefits, creating opportunitiesfor integrated and sustainable rural development (Yang et al., 2010). However, it is worth noting that most of coffee plantations are located in remote rural locations, which demand a fairly substantial time commitment. Figure 7 shows the agro-tourism products which as mainly coffee and tea plantations, and their processing units as well. 


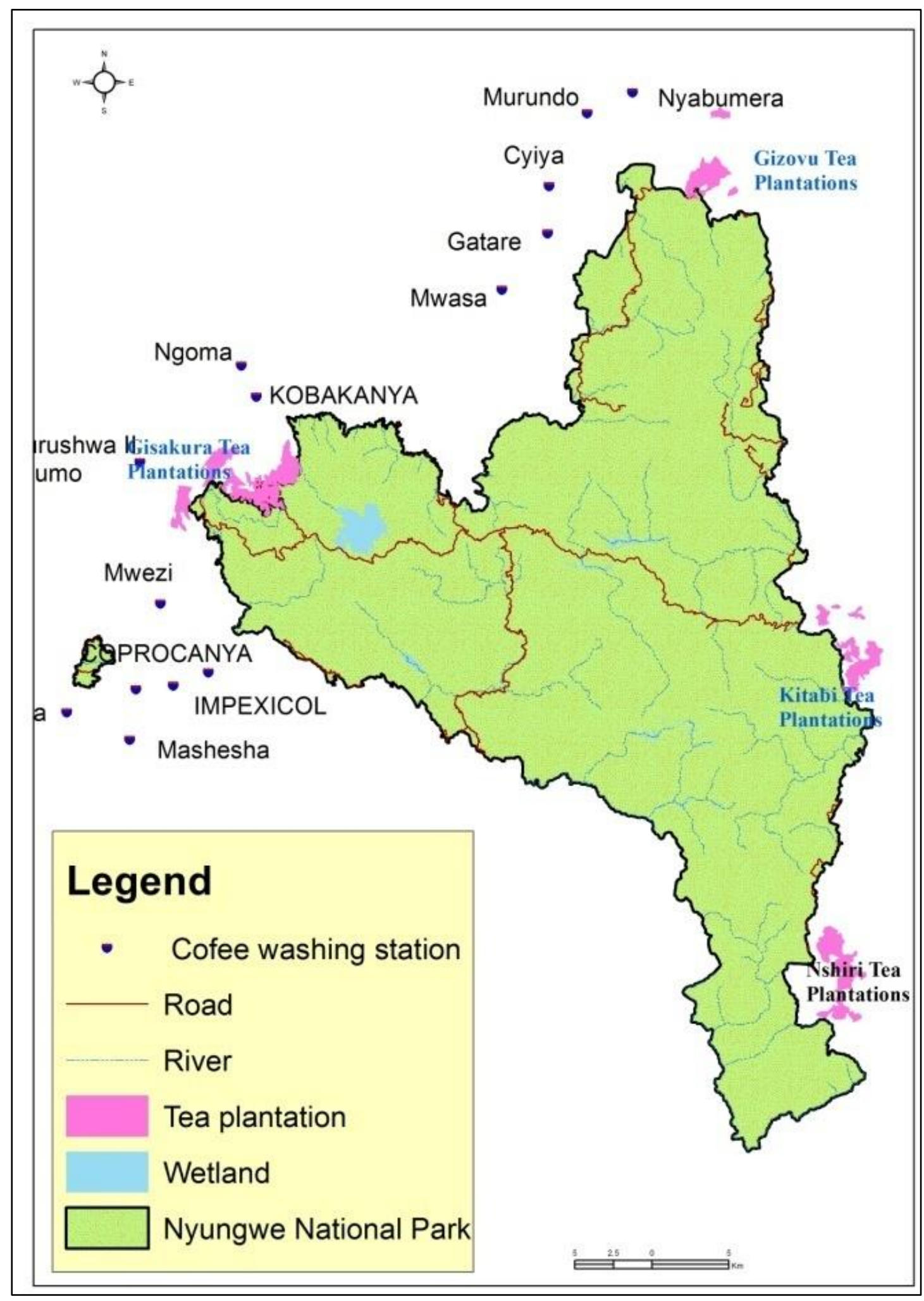

Figure 7: Preferred agro-tourism products around NNP

The coffee, tea and their process in units are seen as the new agro-tourism initiatives in Rwanda that add value to clients' experience in the process. Rwanda's Tourism Master Plan recognizes 
coffee tourism as a potential 'add-on product' to complement the core market of eco-tourism. To fully develop coffee tourism will entail addressing a range of tourism development issues such as changing tourist travel patterns, positioning coffee tourism as an attractive and essential attraction, and addressing transport matters in a remote, poor and infrastructural challenged destinations (Anbalagan and Lovelock, 2014).

\subsection{Reason for not visiting other products}

The overall reason for not visiting Nyungwe ecotourism products is the short time available for tourists. All tourism activity is influenced, to some extent, by the time available to tourists and how they choose to spend that time (Chavas et al., 1989). This can be understood as time-distance constraint in relation to the quality of road and existing transport infrastructure, relative prices, and distance to re locations of the proposed tourism products.

The factors are important ingredients in their own respect in the tourism demand equation (Khadaroo and Seetanah, 2007). Efficient transportation planning and constant upgrading of road infrastructure are therefore required in order to minimize the time-space constraint for more targeting high-spending tourists and promoting ecotourism in and around NNP.

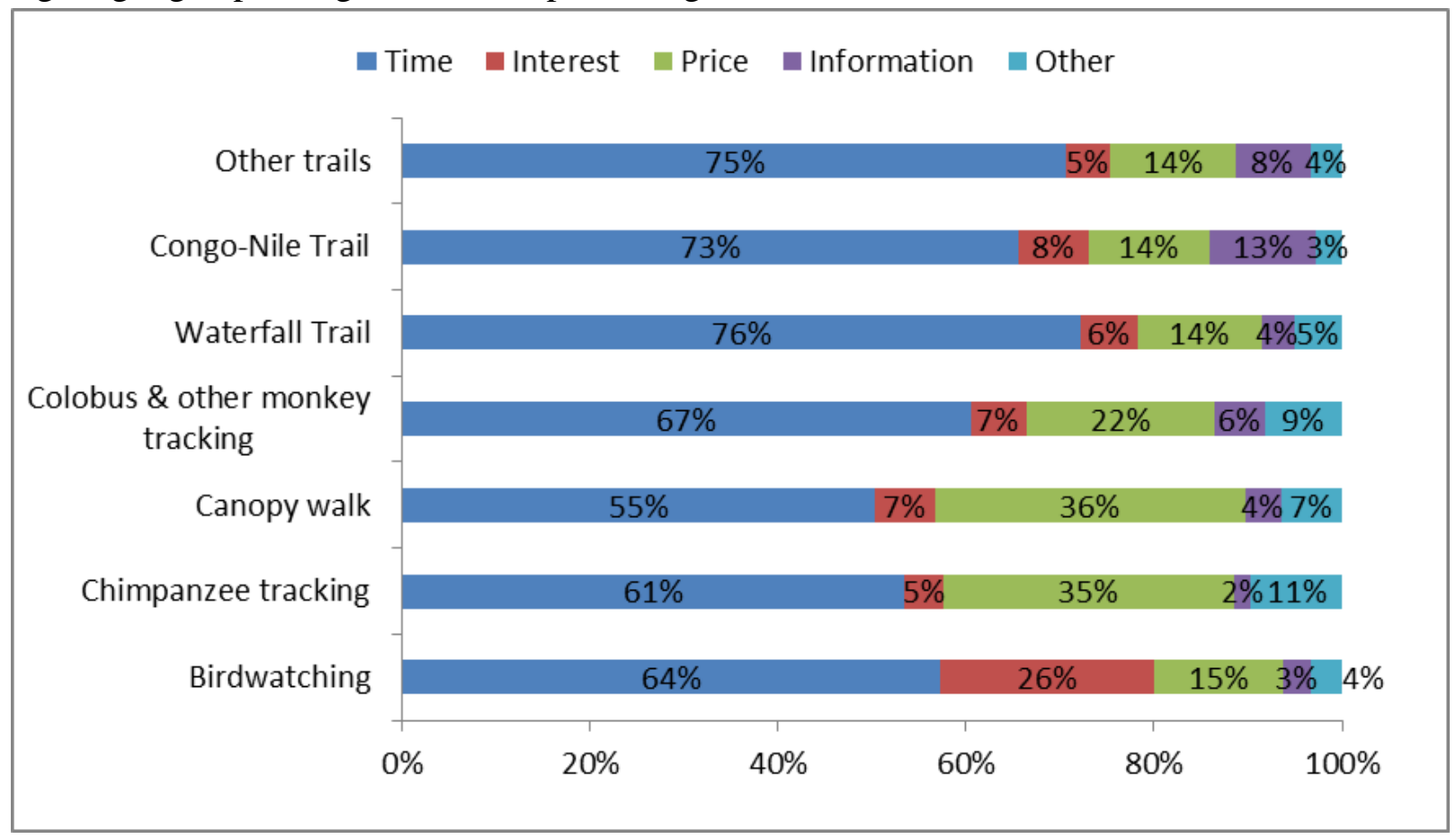

Figure 8: Reason for not visiting other products

Time is one of the few absolutes tourists must face, for it cannot be stored for use at a future date (Truong and Hensher, 1985). Some products where time was the main reason include the waterfall trail, other trails and the Congo Nile Trail. The second main reason is interest, especially for canopy walk with $36 \%$ of the respondents, and chimpanzees tracking (Figure 8). The percentages total exceeded 100 due to the multiple choice option given to respondents. This finding has a 
spatial planning implication to address the transport matters in a remote rural areas and poor road infrastructure challenge in highlighted destinations (waterfall trails and Nile Trail).

\subsection{Criteria for choosing a destination}

Respondents were given a list of aspects to choose when travelling to a destination.

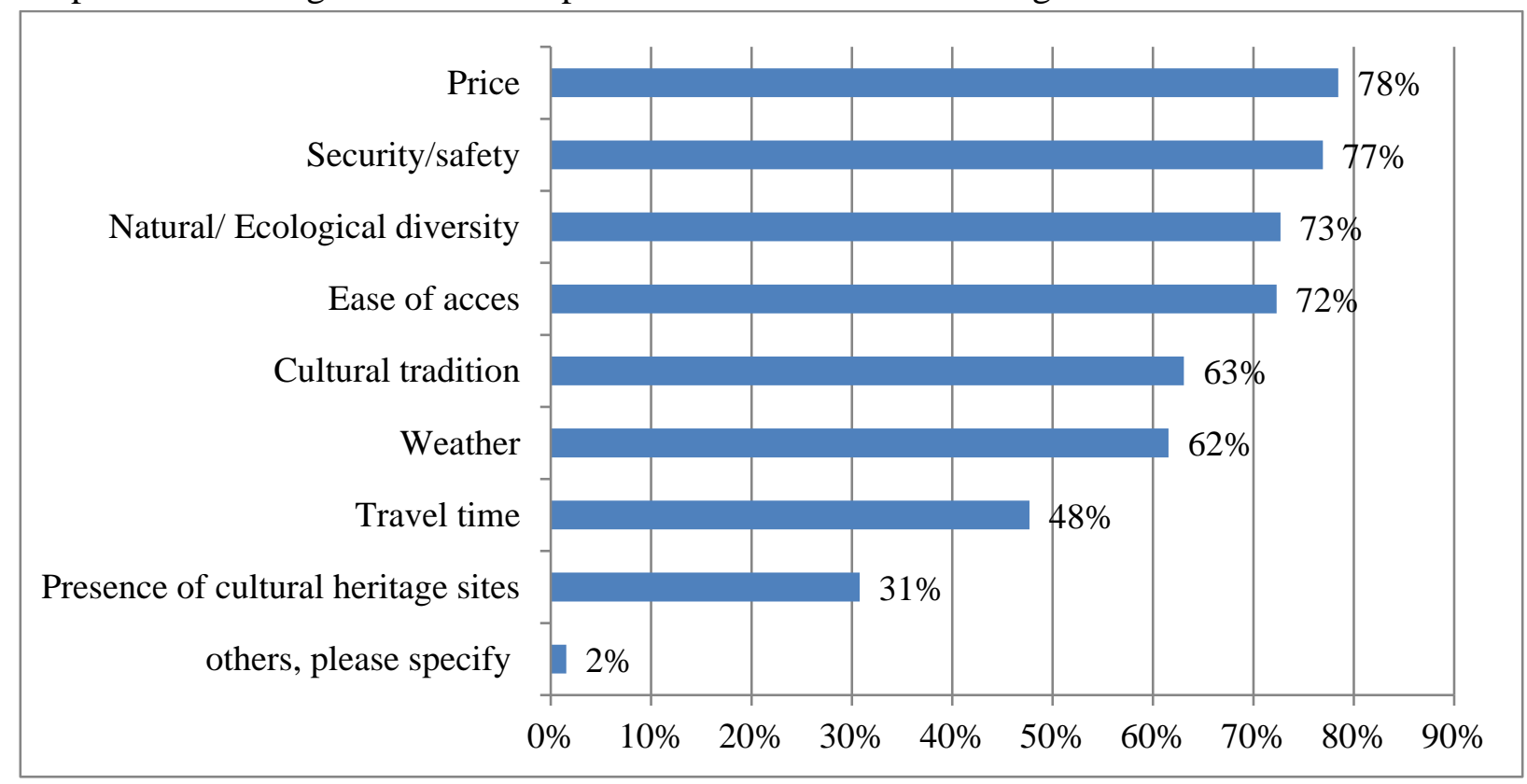

Figure 9: Aspects to consider when choosing a destination

Out of 240 respondents who were asked to choose from a list of aspects they consider before travelling to a destination, price was the main aspect, followed by security and safety, natural or ecological diversity and ease of access (Figure 9). Those who mentioned others did not specify the aspects. The price will also be discussed on tourists' willingness to pay discussed below.

\subsection{Source of information to tourists}

From a list of source of information for tourist, internet was the main source information followed by travel guidebooks and recommendations from a friend or relatives (Figure 10). This finding implies that the Department of Tourism of RDB should invest more in internet communication facilities and infrastructure in and around NNP. There is also a need to keep providing the travel guidebooks in all hotels in Rwanda, and if possible in main public places such airports and base stations. To regularly providing all required information on websites and upgrading the RDB website could also help improve the communication with tourists and accessibility to information by all visitors. 


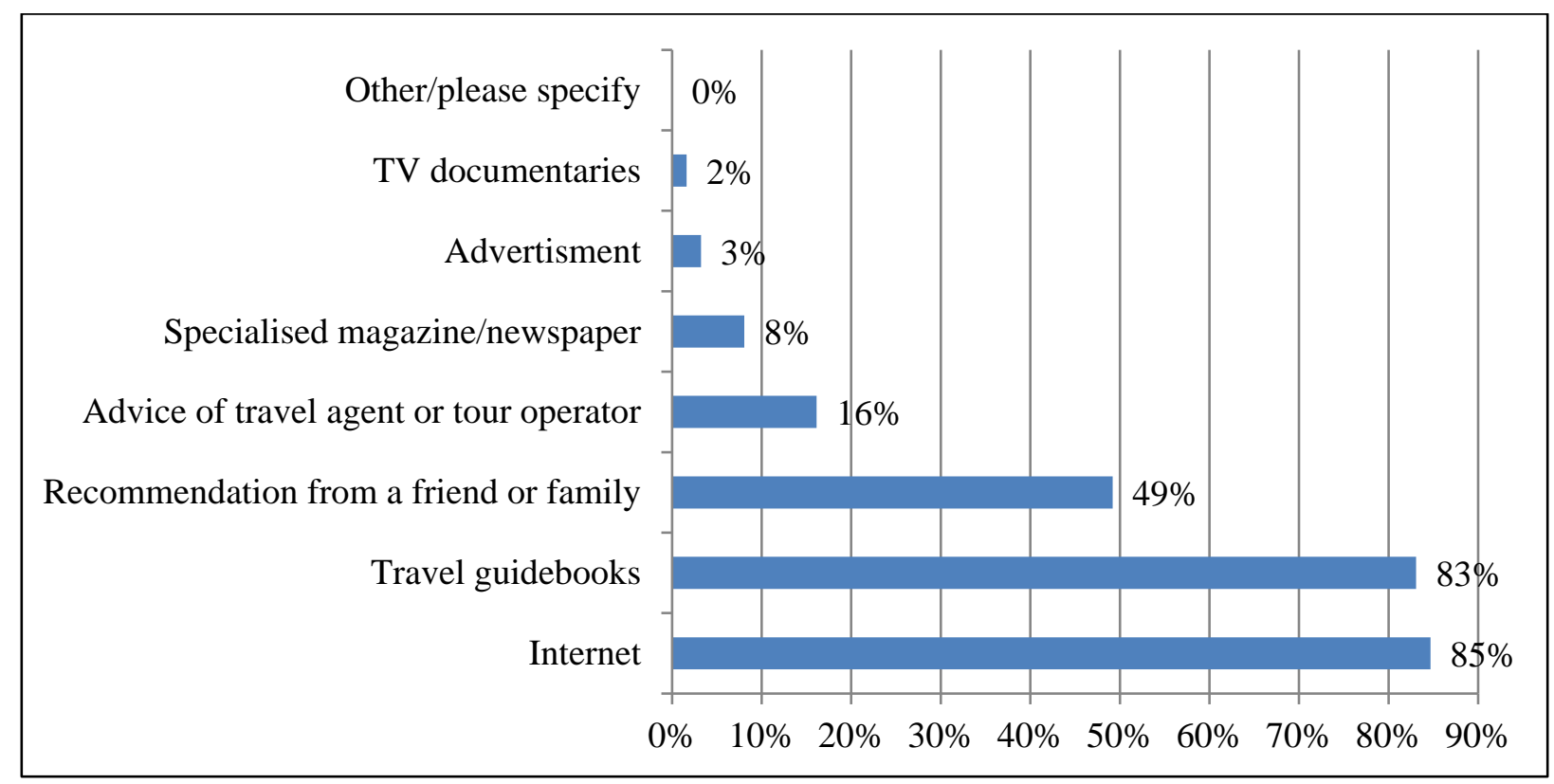

Figure 10: Source of information when choosing a destination

\subsection{Reasons for visiting NNP}

Tourists were given a list of reasons behind their visit to the park. They were also asked to mention other reasons not on the list. The knowledge of the reasons to visit NNP will help the park manager's plan by prioritizing the development of tourism products.

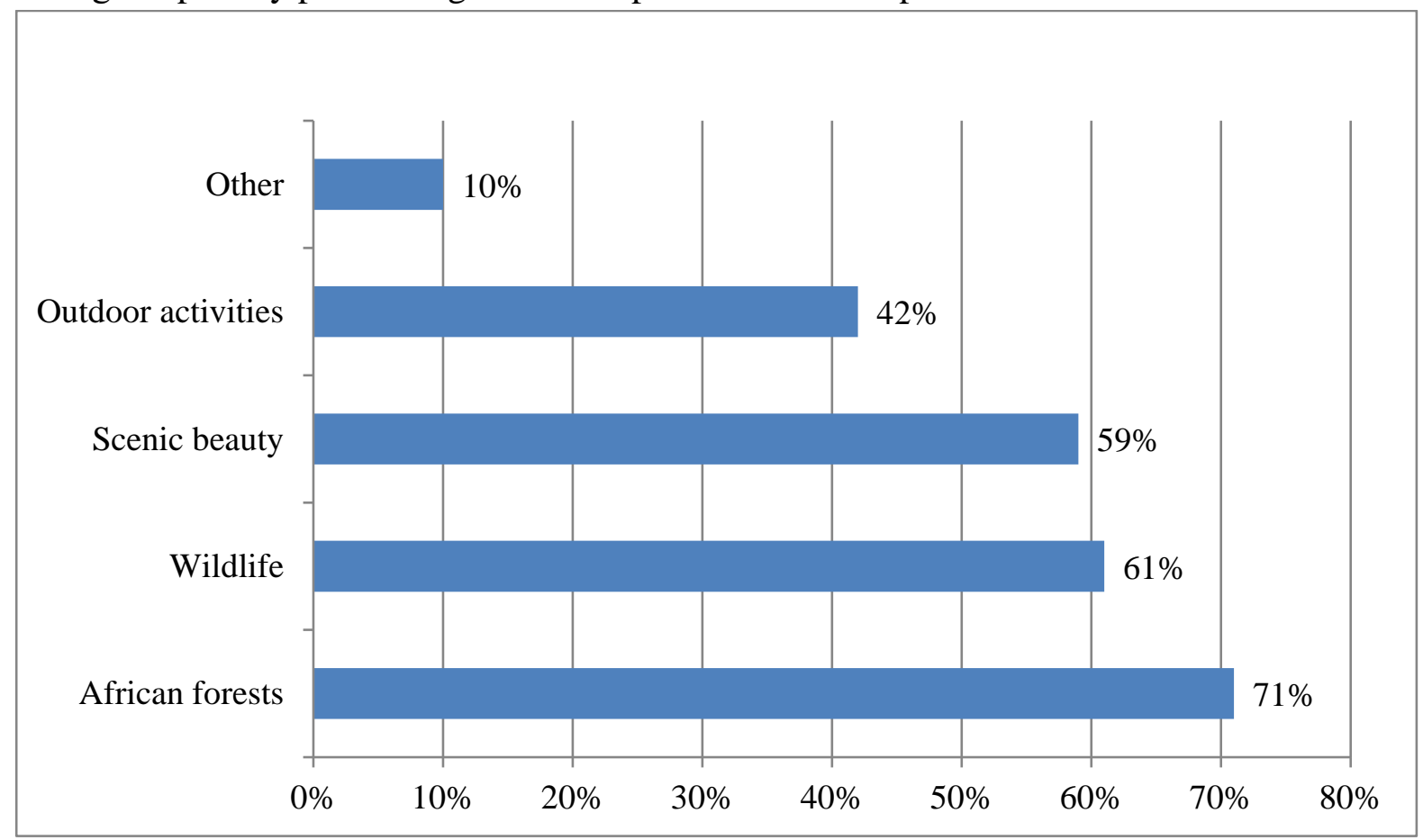

Figure 11: Top reasons to visit Nyungwe National Park 
The main reason to visit NNP was enjoying the Africa forest (Figure 11). Some studies classify NNP as one of the largest and most important montane forests remaining in Africa and recently gazetted as a National Park to protect its extensive floral and faunal diversity. Nyungwe consists of a mixture of primary and secondary forest interspersed with several large marshes (Fashing et al., 2007). The second reason to visit NNP was for the wildlife. The scenic beauty of the destination is the third reason to visit the destination. Among other reasons to visit NNP is that NNP is on the list of the packaged tours together with Volcanoes National Park, home of mountain gorillas. The history of the country attracts some tourists who need to experience the post genocide recovery period and economic development of Rwanda.

Additionally, tourist visitors to NNP are interested by outdoor activities in NNP including the walks from the easiest to the most difficult. NNP is home to thirteen species of primates and four of them are habituated for tourism namely chimpanzees, black and white Angolan colobus monkeys, blue monkeys and grey cheeked-mangabeys. Tourists may also enjoy bird watching. Nyungwe is also home to almost 278 species of birds including twenty seven endemic in the Albertine Rift. Previous studies have also shown that most of tourists come to Nyungwe to enjoy the wildlife viewing (Plumptre et al., 2007; Plumptre et al., 2002). The result from the survey also revealed that respondents were mostly attracted by tree species that are found in NNP. For most international tourists, it is a new experience to hike or stay in those forests.

\subsection{Tourists attitudes towards service and ecotourism products}

Tourists' attitudes toward offered products are represented by level of satisfaction and quality of service, level of satisfaction with quality of products, and willingness to pay ecotourism products.

\subsubsection{Level of satisfaction on quality services}

As presented in Figure 12, the level of satisfaction and the quality of services provided by NNP tourism staff is relatively high. Tourists ranked service of guiding service in NNP at high of satisfaction (very satisfied), followed by customer service and ease of payment. This is justified by the training sessions on guiding and interpretation done by the park guides and other tourism staff. These findings is well in agreement with other sources of information from face book page, twitter account and other information provided by guides and tour operators. Often their comments were very positive when expressing their appreciation for the expertise and helpful nature of the guides, the thrill of the activity, the beauty of the scenery, and the viewing of the wildlife. 


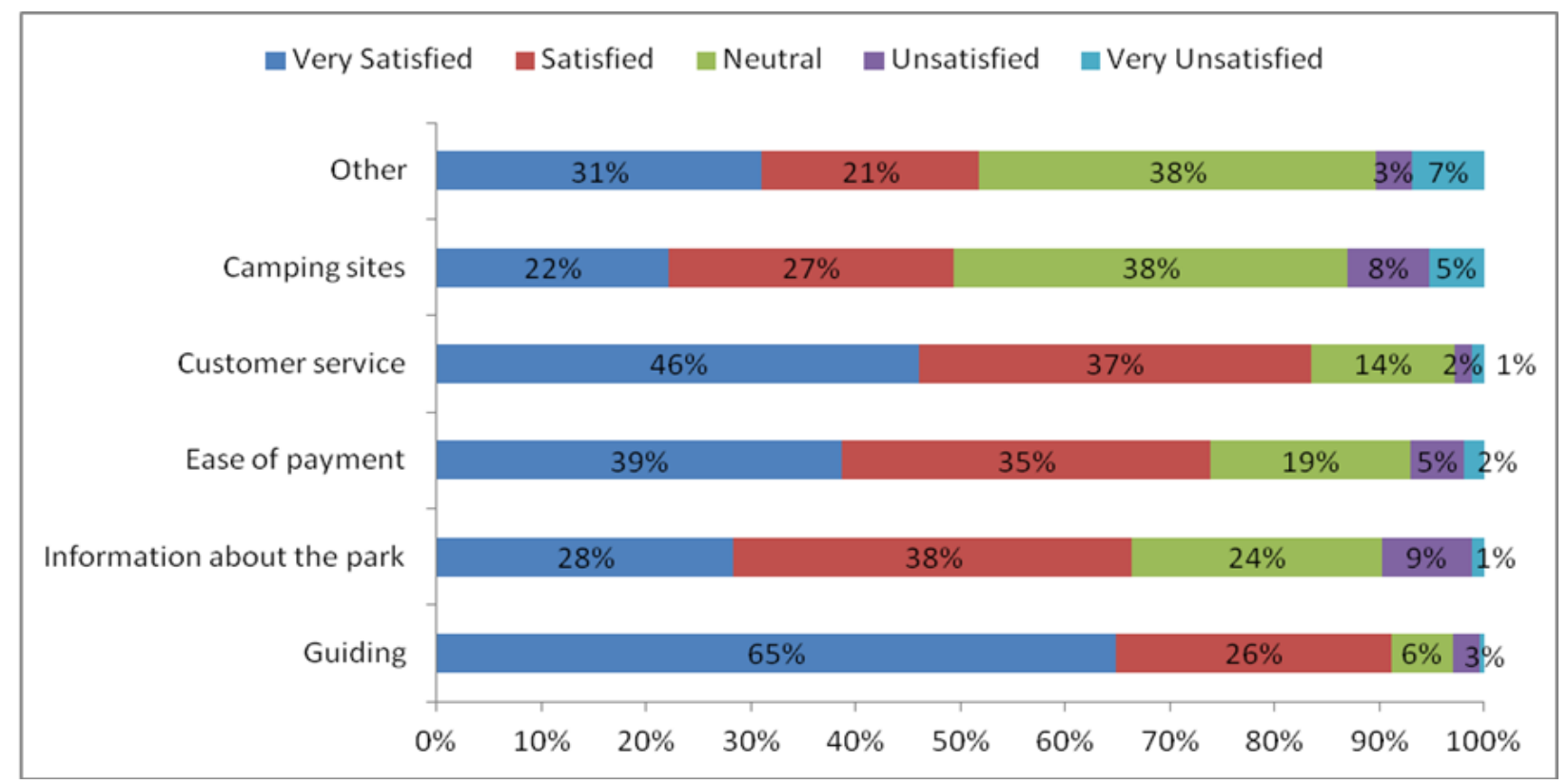

Figure 12: Level of satisfaction and quality services

Despite the high level of satisfaction about the quality of the provided services, the camping site is an area where improvement is most required as many respondents were not satisfied with the services at camping sites (Figure 12). Some clients who booked through inbound tour operators were not aware of the mode of payment or the prices for tourism products in the park; and therefore are headed by tourism wardens responsible for the service delivery. Nyungwe camping sites have been reduced to two from four during the construction of the Visitor Center at Uwinka. This information corroborates with anecdotal information found in the visitor log, comments to the surveyors' and tour operators' feedbacks. Negative comments were mostly related to the lack of information, especially related to activity logistics, strenuousness of the activity, and clarity about the fee structure: "I feel like I was not informed about all different activities by the guides, internet or "very basic" brochure. Now I'm finding out through the questionnaire! Please publish more informative brochure and put info on internet. Finding information prior to arrival was difficult and RDB office in Kigali gave wrong information. An information board in Butare and Kigali would be useful to describe activities, start times, and cost....etc." The ways that visitors and stakeholders use to provide feedback (comment logs, website blogs, etc) have not yet been institutionalized and incorporated into the planning of activities and associated fees at NNP.

\subsubsection{Level of satisfaction with the quality of products}

With regards to level of satisfaction with the quality of the products in the park, most respondents were very satisfied with the quality of the trails in the park (Figure 13). However, 75\% of respondents were neutral about the level of satisfaction when using the Congo Nile Trail. The reason is that the Congo Nile Divide trail is not well known to tourists. It is the longest trail in the park, dividing the park into two sections, the Nile river section and Congo River section. The hike takes three days and two nights. Of those who did it, $25 \%$ were unsatisfied with the quality of this 
trail. When looking at the statistics of the park, an average number of tourists hiking to this trail is less than 5 per month.

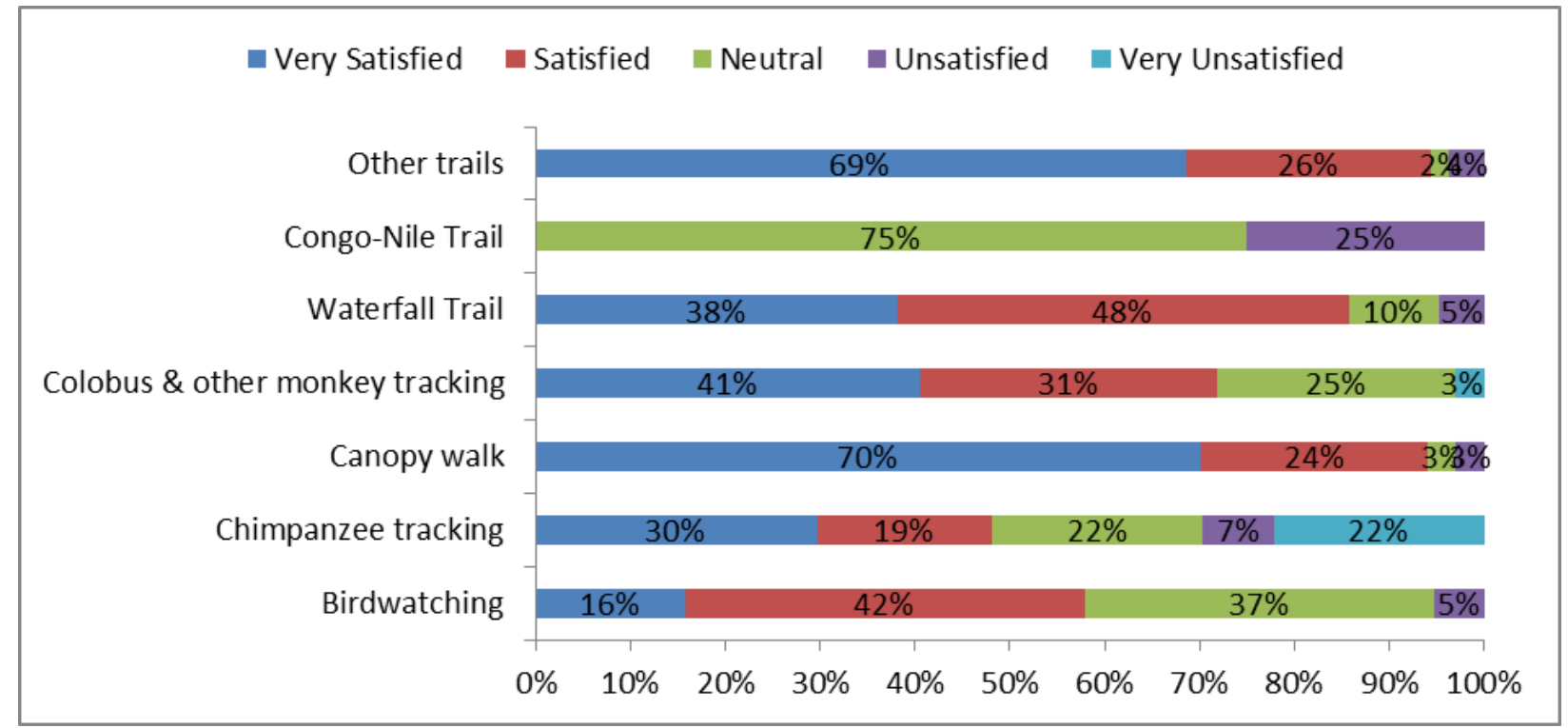

Figure 13: Level of satisfaction with the products

The canopy walkway was new at the time of this study, and the second most attractive tourism product in NNP, as the majority of tourists were very satisfied with the quality of the canopy walk. This satisfaction is justified by a visitor survey to find out how much money tourists would pay as entrance fee to the forest. As per Figure 13, a big number of tourists who participated in the survey was also very satisfied with colobus tracking experience. Two groups of colobus monkeys are visited and a small group of 50 individuals moves around the tea plantations which are located at a walking distance from the reception and the lodge. The main complaints of tourists were about the small group of colobus being near where tourists were not engaging much physical effort to track them and hence the lack of value for money.

The waterfall commonly called 'isumo' in the local language, takes its source from a swamp known as Kamiranzovu. Being accessible from the lodge and reception, 38\% of the respondents were very satisfied and $48 \%$ satisfied. Chimpanzees' tracking in NNP is done at two sites of Mayebe and Cyamudongo forests. The two communities are still under habituation to human presence. The tracking experience is not the same every day and the level of satisfaction varies from day to day. The number of tourists tracking chimpanzees to one site is limited to eight due to universal great apes visitation protocol, limiting some tourists to track them. Despite the limited number of chimpanzees to be visited, some tourists are very satisfied with this product while others are interested in chimpanzees tracking.

\subsubsection{Willingness to pay for ecotourism products}


In order found out how much visitors would like to pay for ecotourism products helping the park management to plan accordingly, we explored the information from visitor's book. Below are a selected number of comments from the visitor book: "Can you please reconsider this pricing policy. Of course, people should pay for sustaining the RDB structures, but this should be reasonable and not just because people will pay once they have come all the way here. Some of the prices of activities are high to be affordable; it shortens ones length of stay. People are complaining about the cost to Visit Nyungwe National Park, because they have to pay for every trail. Too expensive for families... Was too expensive for what we did. Do you imagine U\$70 for walking in the forest! We came only to do the trails, but since they were $\$ 30$ we couldn't go and had to leave the park".

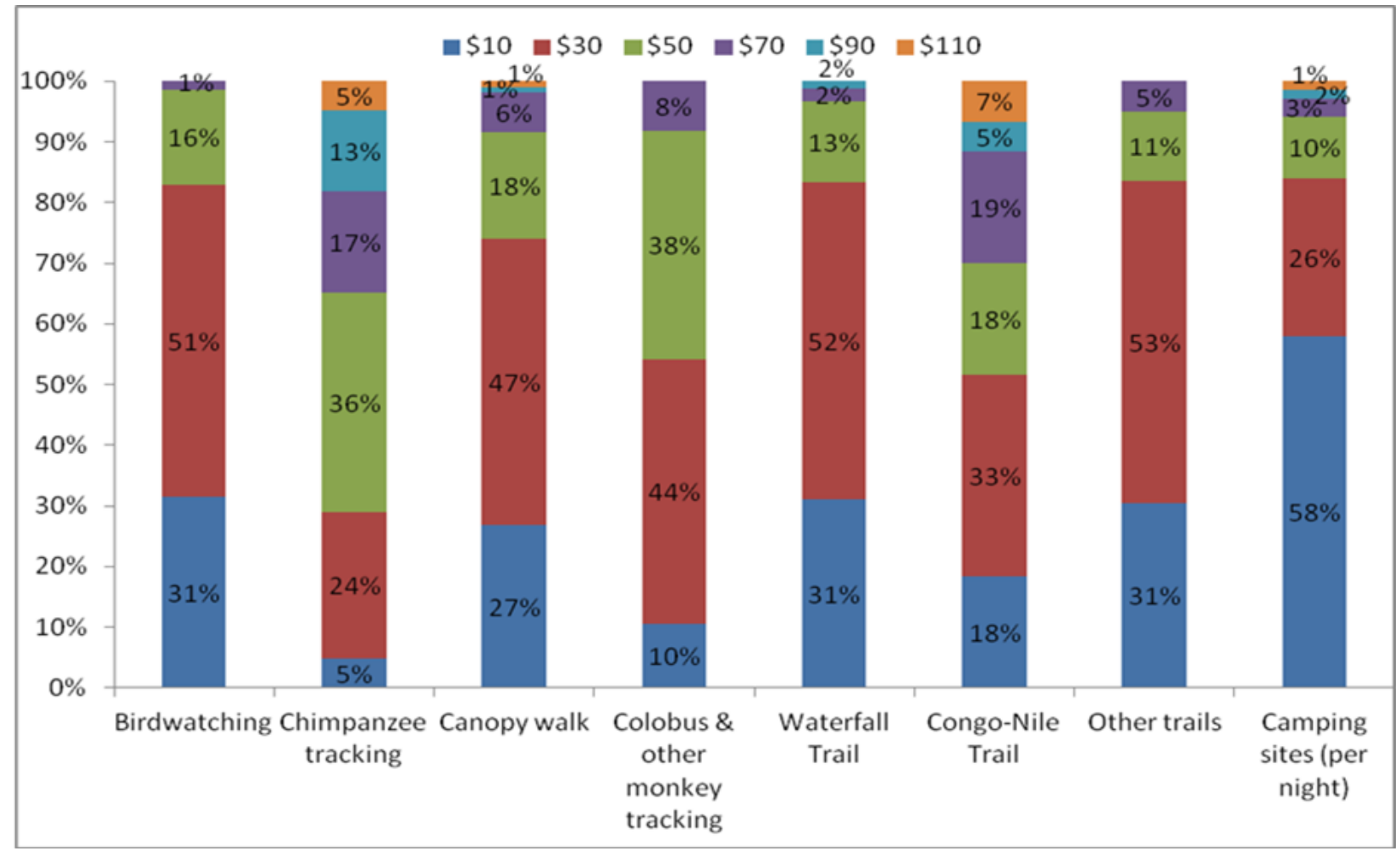

Figure 14: Tourists willingness to pay

The opportunity to see a wide variety of Albertine Rift endemic bird species coupled with the park's hilly terrain allowing good views of the forest canopy makes NNP an ideal place for bird watching. The majority of tourist would like to pay between 30 US\$ and 50 US\$ while a small number of tourists want to pay to pay 70 US\$ which is the current price for bird watching (Figure 14). NNP as a bird watching destination is not very known to many as it offers a tourism activity for people with a passion for birds or a selected group of amateurs. Chimpanzees in NNP are one of the main flagships for the park's products including the canopy walkway. The biodiversity survey conducted in 2006 showed a population of 400 chimpanzees scattered in the park. Only two communities of chimpanzees are habituated for tourism. One more community is under habituation. While the current price of chimpanzees tracking experience is 90 US\$, this study 
found that many tourist are also willing to pay between 30 US\$ and 50 US\$ for chimpanzees tracking; and small fraction of respondent is willing to pay this price.

The canopy walkway in NNP is a new product built and launched in 2010 under the auspices of the United State Agency for International Development (USAID) Program and Rwanda Development Board (RDB) (Cowles et al., 2013). As a fund to RDB, Nyungwe canopy walk is serving as a flag ship ecotourism product, being charged 60 US\$ even if most tourists want to pay from 10 and 30 US\$ as entrance fee. Since its opening in 2010, it attracts about 2500 tourists per year. This indication is good since the main purpose of the facility is not only to provide an opportunity to experience the uniqueness of the forest but more importantly the idea is to promote environmental awareness and further enhance nature appreciation amongst the public. Nyungwe canopy provides pedestrian access to the forest canopy. It consists of bridges between trees in the canopy of a forest, mostly linked up with platforms inside or around the trees. The canopy walk tourism in NNP is a strategy to diversify tourism attractions. As the only attraction of its kind in East Africa, Nyungwe canopy walk is aimed at encouraging tourists to spend a longer time in Rwanda.

Only in NNP can tourists find large groups of colobus, up to six hundred individuals travelling together. Other types of monkeys available for tourism in NNP are the blue monkeys, and greycheeked mangabeys. Forty four percent of the respondents were willing to pay 30 US\$, and $37 \%$ would pay $50 \%$. The current price for monkey tracking is 60 US\$. The waterfall walk in NNP is known for its attractiveness, attracting about 2,500 tourist visits annually. There are 17 trails within NNP on sale. The waterfall trail has been marketed a standalone product alongside other trails. This trail is charged 50 US\$ and other trails, except Congo Nile Divide Trail, are charged 40\$. Fifty two percent of the respondents would like to pay $30 \$$ and $31 \%$ of them would pay 10 US\$.

A high percentage of tourist recommended that the reasonable prices for the campsites should varies between 10 US\$ and 30 US\$. Available comments from tourists were negative about the price charged for camping sites in the park which is $30 \$$ per night: nice location; staff very obliging to bring containers of water and warm water; camping expensive; no running water, no flushing toilet or shower; very uncomfortable, need to provide a place to wash cutlery and plates; a solar heater for hot water rather than wood burning; more variety of food; mirrors in the bathrooms".

\subsubsection{Tourists preferences for ecotourism development}

A large number of respondents admitted that their preferences to consume ecotourism products needs to be taken into considerations while planning and developing ecotourism products in NNP. Only $14 \%$ of the respondents were neutral. They were then asked to give reasons in the next question. Tourists were given a list of reasons to choose such as improved quality service and product, reduced environmental impact, improved infrastructure, and meeting their expectations. 


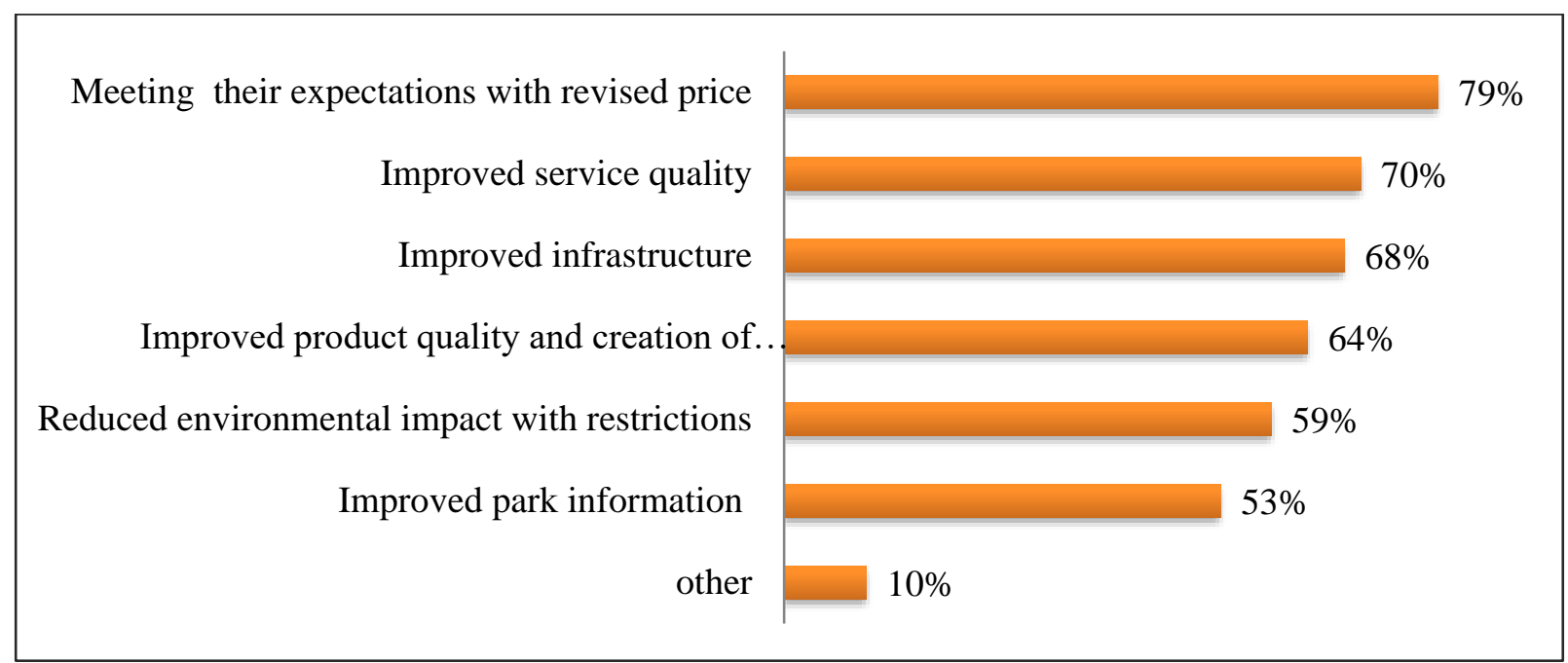

Figure 15: Why tourists' preferences need to be considered

With regards to tourist suggestions to park managers for sustainable tourism planning, most of respondents suggested that the park should revise the price to visit the park and improved service quality and road infrastructure. The tourists' comments and suggestions would help the park management to review the service quality provided ranging from guiding, transport and conflicts resolution. The main reason is to meet tourists' expectations, improved infrastructure and product quality, reduced environmental impact and improved park information. Some other mentioned reasons relates to improved business and competitiveness as well as branding position of the park.

\section{Conclusion}

This research discussed the understanding of tourist' preferences as a prerequisite for ecotourism planning and development, as discussed in the previous chapters. Those preferences while visiting ecotourism products, according to Hearne and Salinas (2002) evolved around five attributes namely infrastructure, information, user restriction, viewpoints and prices. By considering top reasons attracting tourists to the park, the park management should keep NNP undisturbed by reducing threats such as encroaching, tree cutting, fires and poaching to meet tourist expectations who want to visit unique African forest and wildlife. The planning process should emphasize on monitoring the impact on biodiversity, wildlife counts and improvement reducing forest threats. As far as quality service and product quality are concerned, the park management should keep refreshing park staff through trainings and courses and improving park infrastructure. The park planning policy should not only consider capacity building of park staff but also it should monitor its implementation.

Considering a number of products not available in and around the park, as mentioned by respondents in this research, the park management should consider those products while planning for ecotourism. As shown during the course of the research, considering different stakeholders while planning for ecotourism is of great importance. A key to the success of ecotourism is the 
formation of strong partnerships so that the multiple goals of conservation and equitable development can be met. Partnerships may be difficult because of the number of players involved and their different needs, but forging relationships is essential (Drumm and Moore, 2005). As mentioned by respondent reasons for not visiting other tourism products, time and price occupied a big percentage. The marketing plan for the park should put in place a packaging system that allows tourists to stay longer. In addition, product diversification should also help in allowing tourists make wider choice. The planning process should consider the availability of clear information on websites that tourists should check prior to travel to the park. The park should consider tourists preferences as stated in the research through surveys and /or interviews and the data will help during planning and developing ecotourism products.

The willingness to pay by the respondents should be given a priority while pricing ecotourism products. Greater information dissemination to visitors to increase their awareness of fee structure and highlight the ways fees are used may also increase willingness to pay. Similarly, it is vital that information to be gathered by managers through regular monitoring of park revenues, visitation patterns, local benefits and periodic evaluations of willingness to pay to assess the performance of pricing strategies against clearly defined policy objectives. Considering an increase of tourists visiting ecotourism destinations worldwide, there is a need to take into considerations consumer choice and preferences while planning and developing ecotourism products. Tourists in NNP have been increasing in numbers and as one of the key stakeholders in ecotourism development, information data on tourists should add more on tourists' numbers and revenues.

Apart from ecotourism planning, consumer preferences should also be the basis for marketing strategies (Van Raaij, 1986) and consumer policy. It is better to evaluate consumer behavior with regard to existing touristic products, in order to develop new touristic products or change existing ones. In addition, touristic products should not be simple or one-sided. Many tourists have a need for variety, especially during a long vacation. Understanding consumer preferences is very useful for developing tourism products. It is also an integral source of information for promoting tourism products and highlights how to sell tourism products particularly in this globalized era, in which the patterns of tourist traveling is highly influenced by global factors such as the mass media. In short, the study of consumers' preferences is not solely of academic interest but it is also substantially beneficial when practicing managers have the need to know and respond to tourists' needs and wants effectively.

\section{Acknowledgments}

We are thankful to Rwanda Development Board, Tourism Department, Nyungwe National Park, for providing tourism statistics and relevant information that were used in this study. We are grateful to Prof Beth A. Kaplin for proof reading the draft of the manuscript.

\section{References}


Anbalagan, K., and Lovelock, B., 2014, The potential for coffee tourism development in RwandaNeither black nor white: Tourism and Hospitality Research, v. 14, no. 1-2, p. 81-96.

bin Ramlan, M. A., Radam, A., Yacob, M. R., and Yahya, N. A., 2011, Willingness to pay towards the sustainability of Forest Research Institute Malaysia's (FRIM's) canopy walkway: International Journal of Business, Management and Social Sciences, v. 2, no. 3, p. 85-92.

Byers, B., Nsengimana, S., Hakizimana, E., Rutagarama, E., and Granier, L., 2014, Rwanda Environmental Threats and Opportunities Assessment; Report to United States Agency for International Development; November 2014.

Chavas, J.-P., Stoll, J., and Sellar, C., 1989, On the commodity value of travel time in recreational activities: Applied Economics, v. 21, no. 6, p. 711-722.

Chemonics International, 2008, Rwanda Environmental Threats and Opportunities Assessment (ETOA) 2008 Update; United States Agency for International Development, July 2008.

Cheng, S.-w., Xu, F.-f., Zhang, J., and Zhang, Y.-t., 2010, Tourists' Attitudes Toward Tea Tourism: A Case Study in Xinyang, China: Journal of Travel \& Tourism Marketing, v. 27, no. 2, p. 211-220.

Cheng, S., Hu, J., Fox, D., and Zhang, Y., 2012, Tea tourism development in Xinyang, China: Stakeholders' view: Tourism Management Perspectives, v. 2-3, p. 28-34.

Cowles, P., Hoffman, C. A., Hakizimana, E., Zerbock, O., McClintock, E., and Bamwesigye, J., 2013, Evaluation of USAID Investments in Nyungwe National Park: Prosperity, Livelihoods and Conserving Ecosystems; Report to United States Agency for International Development; March 2013.

Crawford, A., 2012, Conflict-Sensitive Conservation in Nyungwe National Park: Conflict analysis; IISD Report: Winnipeg, Manitoba, Canada: International Institute for Sustainable Development, January 2012.

Drumm, A., and Moore, A., 2005, Ecotourism Development: A Manual for Conservation Planners and Managers. Arlington, VA: The Nature Conservancy.

Fagence, M., 1998, Rural and village tourism in developing countries: Third World Planning Review, v. 20, no. 1, p. 107.

Fashing, P. J., Mulindahabi, F., Gakima, J.-B., Masozera, M., Mununura, I., Plumptre, A. J., and Nguyen, N., 2007, Activity and ranging patterns of Colobus angolensis ruwenzorii in Nyungwe Forest, Rwanda: possible costs of large group size: International Journal of Primatology, v. 28, no. 3, p. 529-550.

Fuchs, E. B., 1997, Cable car system with passenger carriers suspended from a suspension and traction cable guided around two deflection pulleys, Google Patents.

Gapusi, R. J., 2007, Regeneration of Indigenous Species in Nyungwe buffer zone for biodiversity conservation and local people's livelihood in Rwanda, Swedish Biodiversity Centre, UPPSALA University.

Government of Rwanda, 2009a, Fourth national report to the convention on biological diversity; Rwanda Environment Management Authority; Ministry of Natural Resources, Kigali, May 2009 
Government of Rwanda , 2009b, Sustainable Tourism Master Plan for Rwanda. Final Report, May 2009. Kigali, Rwanda.

Hamilton, A. C., 1982, Environmental history of East Africa: A study of Quaternary, .London and New York, Academic Press.

Hansen, A., 2012, Tourism value chain analysis for Nyungwe National Park; Final Report to United States Agency for International Development; September 2012

Hearne, R. R., and Salinas, Z. M., 2002, The use of choice experiments in the analysis of tourist preferences for ecotourism development in Costa Rica: Journal of Environmental Management, v. 65, no. 2, p. 153-163.

Huang, R., 2006, Linking tea and tourism: The experience of Hunan Province (China): China Tourism Research, v. 2, no. 4, p. 579-593.

Jolliffe, L., 2007, Tea and tourism: Tourists, traditions and transformations, Channel View Publications.

Jolliffe, L., 2010, Coffee culture, destinations and tourism, Channel View Publications.

Khadaroo, J., and Seetanah, B., 2007, Transport infrastructure and tourism development: Annals of Tourism Research, v. 34, no. 4, p. 1021-1032.

Kushwaha, A., Chatterjee, D., and Mandal, P., Potentials of GIS in Heritage \& Tourism, in Proceedings Geospatial world forum2011, p. 18-21.

Lepp, A., 2007, Residents' attitudes towards tourism in Bigodi village, Uganda: Tourism Management, v. 28, no. 3, p. 876-885.

Luna-Nevarez, C., and Hyman, M. R., 2012, Common practices in destination website design: Journal of Destination Marketing \& Management, v. 1, no. 1-2, p. 94-106.

Masozera, M., and Alavalapati, J., 2004, Forest dependency and its implications for protected areas management: a case study from the Nyungwe Forest Reserve, Rwanda: Scandinavian Journal of Forest Research, v. 19, no. Suppl4, p. 85-92.

Masozera, M. K., 2002, Socioeconomic impact analysis of the conservation of the Nyungwe forest reserve, Rwanda: University of Florida.

McAdam, D., 1999, The Value and Scope of Geographical Information Systems in Tourism Management: Journal of Sustainable Tourism, v. 7, no. 1, p. 77-92.

Mehta, H., 2007, Towards an internationally recognised ecolodge certification: Quality assurance and certification in ecotourism, p. 415-434.

Mehta, H., 2010, Authentic ecolodges, Harper Collins.

Ngenzi, Y. K., 2009, Perceived barriers to tourism development in Rwanda as a tourist destination [PhD Thesis: Cape Penninsula University of Technology; CPUT Theses \&Dissertations ; Paper 29.

Perkins, H. E., and Brown, P. R., 2012, Environmental values and the so-called true ecotourist: Journal of Travel Research, p. 0047287512451133.

Plumptre, A. J., 2003, Lessons learned from on-the-ground conservation in Rwanda and the Democratic Republic of the Congo: Journal of Sustainable Forestry, v. 16, p. 71-91. 
Plumptre, A. J., Davenport, T. R., Behangana, M., Kityo, R., Eilu, G., Segawa, P., Ewango, C., Meirte, D., Kahindo, C., and Herremans, M., 2007, The biodiversity of the Albertine Rift: Biological conservation, v. 134, no. 2, p. 178-194.

Plumptre, A. J., Kayitare, A., Rainer, H., Gray, M., Munanura, I., Barakabuye, N., Asuma, S., Sivha, M., and Namara, A., 2004, The socio-economic status of people living near protected areas in the Central Albertine Rift: Wildlife Conservation Society (WCS), New York.

Plumptre, A. J., Masozera, M., Fashing, P. J., McNeilage, A., Ewango, C., Kaplin, B. A., and Liengola, I., 2002, Biodiversity surveys of Nyungwe forest reserve in SW Rwanda; WCS Working Paper No.19.

REMA, 2011, Atlas of Rwanda's Changing Environment: Implications for Climate Change Resilience; Rwanda Environment Management Authority; Kigali, Rwanda.

Richmond, A. K., Malcomb, D., and Ringler, K., 2015, Household vulnerability mapping in Africa's Rift Valley: Applied Geography, v. 63, p. 380-395.

Rwanda Development Board, 2011, The Nyungwe National Park Management Plan 2012-2021; Rwanda Development Board Tourism \& Conservation Department; December 2011.

Rwanda Office of Tourism and National Parks, 2005, Nyungwe National Park General Management 2006-2010; Rwanda Office of Tourism and National Parks; Kigali, Rwanda.

Seibel, M., 2005, An evaluation of canopy tourism in Costa Rica: The Newsletter of The International Canopy Network v. 12, no. 1.

Seibel, M., 2013, Forest Canopy Tourism: Analyzing a Flagship Attraction in the Ecotourism Arena from a Political Ecology Perspective, Treetops at Risk, Springer, p. 361-365.

Seyler, J., and Mugemana, J. M. V., 2003, Rwanda environmental threats and opportunities assessment: Biodiversity \& Sustainable Forestry (BIOFOR); Report to United States Agency for International Development, February 2003.

Sharlow, D., and Duffy, H., 2012, Guide to Sustainable Mountain Trails in Support of Ecotourism Nyungwe National Park, Rwanda.

Sutherland, W. J., 2008, The conservation handbook: research, management and policy, John Wiley \& Sons.

Tapper, R., and Cochrane, J., 2005, Forging links between protected areas and the tourism sector: How tourism can benefit conservation, Paris United Nations Environment Programme, Paris.

Truong, T. P., and Hensher, D. A., 1985, Measurement of travel time values and opportunity cost from a discrete-choice model: The Economic Journal, p. 438-451.

UNEP, 2008, Africa: Atlas of Our Changing Environment; Division of Early Warning and Assessment (DEWA), United Nations Environment Programme (UNEP), Nairobi, Kenya.

UNEP, 2011, Rwanda From Post-Conflict to Environmentally Sustainable Development, United Nations Environment Programme, Nairobi, Kenya.

UNWTO, 2008, Rwanda Tourism Development Master Plan: UNWTO Development Assistance 2008; Annual Report of the World Tourism Organization on Development Assistance 
Activities; World Tourism Organization Development Assistance Department Capitán Haya.

UNWTO, 2012, International tourism on track to hit one billion by end of 2012.From: http://media.unwto.org/en/press-release/2012-09-12/international-tourism-track-hit-onebillion-end-2012. Retrieved 30 October 2015.

Van Raaij, W. F., 1986, Consumer research on tourism mental and behavioral constructs: Annals of Tourism Research, v. 13, no. 1, p. 1-9.

Vedder, A., 1988a, Conservation of the Afromontane Forests of Rwanda, with Focus on Nyungwe Forest Reserve: Final report. WCS/ORTPN/DGF.

Vedder, A , 1988b, Conservation of the Nyungwe Forest. Final Proposal to USAID Biodiversity Program, January 1988.

Walpole, M., 2004a, Nyungwe Tourism Development Strategy, Wildlife Conservation Society, Rwanda. .

Walpole, M., 2004b, Tourism Development Strategy for Nyungwe Forest, Rwanda. ORTPN and WCS.

Yang, Z., Cai, J., and Sliuzas, R., 2010, Agro-tourism enterprises as a form of multi-functional urban agriculture for peri-urban development in China: Habitat International, v. 34, no. 4, p. 374-385. 